\title{
Chronic lithium treatment alters the excitatory/ inhibitory balance of synaptic networks and reduces mGluR5-PKC signalling in mouse cortical neurons
}

\author{
Anouar Khayachi, PhD; Ariel Ase, PhD; Calwing Liao, MSc; Anusha Kamesh, MSc; \\ Naila Kuhlmann, PhD; Lenka Schorova, PhD; Boris Chaumette, MD, PhD; \\ Patrick Dion, PhD; Martin Alda, MD, PhD; Philippe Séguéla, PhD; \\ Guy Rouleau, MD, PhD; Austen Milnerwood, PhD
}

\begin{abstract}
Background: Bipolar disorder is characterized by cyclical alternation between mania and depression, often comorbid with psychosis and suicide. Compared with other medications, the mood stabilizer lithium is the most effective treatment for the prevention of manic and depressive episodes. However, the pathophysiology of bipolar disorder and lithium's mode of action are yet to be fully understood. Evidence suggests a change in the balance of excitatory and inhibitory activity, favouring excitation in bipolar disorder. In the present study, we sought to establish a holistic understanding of the neuronal consequences of lithium exposure in mouse cortical neurons, and to identify underlying mechanisms of action. Methods: We used a range of technical approaches to determine the effects of acute and chronic lithium treatment on mature mouse cortical neurons. We combined RNA screening and biochemical and electrophysiological approaches with confocal immunofluorescence and live-cell calcium imaging. Results: We found that only chronic lithium treatment significantly reduced intracellular calcium flux, specifically by activating metabotropic glutamatergic receptor 5. This was associated with altered phosphorylation of protein kinase $\mathrm{C}$ and glycogen synthase kinase 3 , reduced neuronal excitability and several alterations to synapse function. Consequently, lithium treatment shifts the excitatory-inhibitory balance toward inhibition. Limitations: The mechanisms we identified should be validated in future by similar experiments in whole animals and human neurons. Conclusion: Together, the results revealed how lithium dampens neuronal excitability and the activity of the glutamatergic network, both of which are predicted to be overactive in the manic phase of bipolar disorder. Our working model of lithium action enables the development of targeted strategies to restore the balance of overactive networks, mimicking the therapeutic benefits of lithium but with reduced toxicity.
\end{abstract}

\section{Introduction}

Bipolar disorder is a major psychiatric illness that affects $1 \%$ to $3 \%$ of the population worldwide, and it is 1 of the top 10 causes of disability. ${ }^{1,2}$ Bipolar disorder starts in adolescence and has a lifelong course, characterized by frequently disabling episodes of mania and depression, often associated with psychosis and suicide. ${ }^{3}$ The etiology of bipolar disorder is complex and unclear, but genetic and environmental factors have been implicated. At present, except for very rare cases, no monogenic cause has been consistently identified, and in genome-wide association studies, hits have been found in varied biological processes, including pathways related to intracellular signal transduction, glutamate synaptic function, hormone signalling and immune system regulation. ${ }^{4-6}$ The unknown cause and apparent genetic heterogeneity of bipolar disorder are challenging for research efforts, especially those aimed at developing appropriate disease models.

Lithium is an effective treatment for mania and has consistently been shown to reduce suicide and overall mortality. ${ }^{7}$ Despite its narrow therapeutic range and potential adverse effects - such as tremor, polyuria, decreased thyroid function and renal toxicity in a minority of patients ${ }^{8}$ - lithium remains the first-line treatment for the prevention of both manic and depressive episodes in bipolar disorder. For many people with bipolar disorder, it is the most effective mood stabilizer, ${ }^{9,10}$ and in addition to reducing suicide risk, it often enables patients to regain social and occupational function. ${ }^{7}$ Despite its widespread use for more than 60 years as a

Correspondence to: A.J. Milnerwood, Department of Neurology and Neurosurgery, McGill University, Montréal, QC H3A 2B4; austen.milnerwood@mcgill.ca

Submitted Sep. 28, 2020; Revised Dec. 21, 2020; Revised Jan. 20, 2021; Accepted Jan. 30, 2021

DOI: $10.1503 / j p n .200185$ 
treatment for bipolar disorder, lithium's mode of action needs to be better understood, as does the reason why it is effective in only about $30 \%$ of people with bipolar disorder. ${ }^{11,12}$

Studies aimed at elucidating lithium's mode of action have found macroscopic changes in brain structure ${ }^{13}$ and alterations at the cellular level. ${ }^{14}$ For the latter, acute lithium administration has been shown to increase glutamate signalling. ${ }^{15,16}$ In contrast, longer-term chronic treatment over 6 to 7 days confers protection against glutamateinduced excitotoxicity by reducing $N$-methyl-D-aspartate (NMDA) receptor-dependent calcium flux. ${ }^{17}$ It has also been shown that lithium alters various intracellular signalling cascades by decreasing second messenger and calcium signalling while enhancing or inhibiting the activity of several enzymes and kinases, such as matrix metalloproteinases, glycogen synthesis kinase 3 (GSK3), extracellular-regulated kinase/mitogen-activated protein kinase and inositol monophosphate phosphatase ${ }^{14,18-20}$ The resulting alterations to intracellular signalling likely also converge on the regulation of gene expression, synaptic transmission and plasticity, blood-brain barrier integrity, neuroprotection and circadian biology.

Several genomic studies have correlated specific loci with lithium responsiveness, ${ }^{21}$ suggesting a shared genetic predisposition to both disease and response to treatment. Single nucleotide polymorphisms (SNPs) in the PLCG1 gene have been associated with response to lithium, indicating that the phospholipase C (PLC)-phosphatidylinositol4,5biphosphate (PIP2)-inositol triphosphate (IP3) signalling pathway may be an important target of lithium. Interestingly, recent data ${ }^{22}$ showed an association between a SNP in the GRM5 gene encoding the metabotropic glutamate receptor 5 (mGluR5) and response to lithium, suggesting that mGluR5 activity and downstream PLC-IP3 signalling is also involved in the therapeutic action of lithium. Other studies have found SNPs associated with bipolar disorder in the GRIN2A $A^{6}$ and GRIA2 genes that encode NMDA and $\alpha$-amino-3-hydroxy-5-methyl-4-isoxazolepropionic acid (AMPA) receptor subunits, respectively. Intriguingly, only SNPs in GRIA2 were associated with lithium responsiveness, ${ }^{5,23}$ suggesting that lithium alters the regulation of $\mathrm{Ca}^{2+}$ permeable AMPA receptors. Beyond genomic association, it remains unclear how lithium interacts with mGluR5, PLCG1 and GluA2 signalling to produce the beneficial outcome in lithium-responsive patients.

In the present study, we sought to establish a holistic appreciation of the neuronal consequences of chronic lithium exposure in mouse cortical neurons, and to begin to determine the underlying mechanisms of action. We performed mRNA sequencing in neurons treated chronically with lithium and discovered altered transcriptional regulation of genes involved in glutamate receptor trafficking and intracellular calcium signalling. We found that chronic (but not acute) lithium treatment significantly reduced excitatory receptor-mediated intracellular calcium flux, specifically through the mGluR5 receptor. This was associated with altered phosphorylation of protein kinase C (PKC) and GSK3, reduced neuronal excitability and several alterations to syn- apse function. Specifically, chronic lithium exposure reduced excitatory synapse activity and density, and it increased inhibitory synapse activity and density. Consequently, lithium treatment altered the excitatory-inhibitory balance in the network, favouring inhibition. Together, the results shed light on how lithium may dampen neuronal excitability and the activity of the glutamatergic network, both of which are predicted to be overactive in the manic phase of bipolar disorder. ${ }^{24-26}$

This discovery also strengthens the potential clinical use of lithium to treat disorders with altered excitatoryinhibitory network activity, such as epilepsy and several forms of autism. This study could also help to develop targeted strategies for restoring the balance of overactive networks, mimicking the therapeutic benefits of lithium but with reduced toxicity.

\section{Methods}

Full details on materials and methods can be found in Appendix 1, available at jpn.ca/200185-a1.

\section{Primary neuronal cultures and animals}

We prepared cortical neurons from wild-type embryonic (E15.5) C57BL/6 mice as previously described. ${ }^{27}$ Animals were maintained in the Centre for Neurological Disease Modelling according to the regulations of the Canadian Council on Animal Care (AUP 2017-7888B). Briefly, cortical neurons were plated in Neurobasal medium (ThermoFisher 21103049) supplemented with $1 \times$ B27 (ThermoFisher 1750044) and 1× glutaMax (ThermoFisher 35050061) on $60 \mathrm{~mm}$ dishes or $12 \mathrm{~mm}$ glass cover slips (VWR) precoated with poly-D-Lysine (0.1 mg/mL; Sigma). Neurons (600000 cells per $60 \mathrm{~mm}$ dish or 80000 cells per $12 \mathrm{~mm}$ cover slip) were then used at 18 to 20 days in vitro.

\section{Drug treatment}

The therapeutic range of lithium $(\mathrm{LiCl})$ treatment is 0.75 to $1.5 \mathrm{mM}$. In this study, neurons were treated chronically with approximately $1.5 \mathrm{mM} \mathrm{LiCl}$ (Sigma L9650) for 7 days starting at 11 days in vitro post-differentiation. As controls, neurons were treated with approximately $1.5 \mathrm{mM} \mathrm{NaCl}$ (Sigma S5886) to ensure the dishes contained the same amount of chloride as the dishes for neurons treated with $\mathrm{LiCl}$. Experiments were performed at 18 to 20 days in vitro.

\section{Data manipulation and statistical analyses}

Statistical analyses were performed using GraphPad Prism software (GraphPad Software, Inc). All data are expressed as mean \pm standard error of the mean (SEM). We used paired $t$ tests, parametric unpaired $t$ tests or nonparametric Mann-Whitney tests to compare medians of 2 sets. We used 1 -sample $t$ tests with hypothetical values of 100 for controls. We verified normality for all groups using Shapiro-Wilk tests, and $p<0.05$ was considered significant. 


\section{Data availability}

All relevant data are shown in the figures or supplementary figures (Appendix 1). Raw data can be requested from the corresponding author.

\section{Results}

Chronic lithium treatment altered the expression of genes involved in synaptic activity, calcium signalling and neuronal excitability

To identify the cellular processes altered by long-term exposure to lithium, we used a concentration designed to match those used in clinical practice. We looked for detectable changes to neuronal gene expression induced by chronic lithium treatment, using whole transcriptome sequencing in cortical neuron cultures at 18 days in vitro. Thirty genes were differentially expressed relative to controls after 7 days of chronic LiCl treatment (Figure 1A and Appendix 1, Figure S1). Using Reactome and Gene Ontology analyses of gene clusters, we determined which pathways were significantly altered with chronic $\mathrm{LiCl}$ treatment. We identified pathways associated with trafficking of AMPA receptors, and with glutamate binding, activation of AMPA receptors and synaptic activity $\left(p=9.7 \times \mathrm{E}^{-5}\right)$. Pathways associated with calcium ion binding $\left(p=4.9 \times \mathrm{E}^{-4}\right)$, CREB phosphorylation $\left(p=2.5 \times \mathrm{E}^{-4}\right)$ and Ras signalling $\left(p=2.8 \times \mathrm{E}^{-4}\right)$ were also implicated, as were pathways related to neurotransmission by chemical synapses $\left(p=1.1 \times \mathrm{E}^{-3}\right.$; Figure $\left.1 \mathrm{~B}\right)$.

\section{Subtoxic lithium treatment reduced spine density and altered dendritic spine morphology}

The therapeutic window for lithium is very narrow (0.5 to $\sim 1.5 \mathrm{mM}$ ), and the line between efficacy and toxicity is fine. It has been proposed that lithium is toxic at doses greater than $2 \mathrm{mM} .{ }^{28}$ We used a cell viability test to confirm that chronic lithium treatment at approximately $1.5 \mathrm{mM}$ for 7 days in primary cortical neurons had no detectable toxicity (Figure 2C).

Excitatory synapses develop their specialized synaptic structures as they mature, over a similar time frame in vivo and in primary culture. Immature postsynaptic protrusions, filopodia and thin spines reappear on dendrites 4 to 7 days in vitro after excitatory neurites have regenerated, and new contacts begin to form between axons and dendrites. As postsynaptic structures mature, they become shorter, fatter and mushroom-like. By 21 days in vitro, spine densities stabilize, and $80 \%$ to $90 \%$ of protrusions exhibit mature morphology..$^{29-31}$ Several studies have suggested that lithium treatment leads to morphological changes in dendritic spines. ${ }^{32-34}$ To determine whether chronic lithium treatment affected dendritic spine density and maturation, we analyzed the presence and morphology of dendritic protrusions in neurons filled with green fluorescent protein after chronic $\mathrm{LiCl}$ treatment (Figure 2A and B).

Chronic $\mathrm{LiCl}$ treatment slightly reduced the density of protrusions in mouse cortical neurons (Figure 2D; control $8.34 \pm$
$0.21 / 10 \mu \mathrm{m}$ versus chronic $\mathrm{LiCl} 7.33 \pm 0.21 / 10 \mu \mathrm{m}$ ), suggesting a reduction in the number of excitatory synapses. Analyses of the morphology of the remaining protrusions showed a significant reduction of approximately $5.3 \%$ in the number of mature spines (mushroom type; Figure 2E; see Appendix 1 for spine characterization guidelines). No changes occurred in the number of stubby spines ( $25 \%$; Figure $2 \mathrm{~F})$, but the percentage of immature spines (thin and filopodia) increased by approximately $5 \%$ in neurons that received chronic $\mathrm{LiCl}$ treatment; Figure 2G), matching the reduction in mature protrusions. We also observed a trend toward a reduction in the mean head diameter of mature spines with chronic $\mathrm{LiCl}$ treatment, from approximately $0.68 \mu \mathrm{m}$ to approximately $0.64 \mu \mathrm{m}$ (Figure 2H). Together, the data show that chronic $\mathrm{LiCl}$ treatment resulted in fewer mature spines that tended to be smaller, indicating that lithium affected either spine maturation or the maintenance of spine maturity in primary mouse cortical neurons.

\section{Lithium induced excitatory and inhibitory synaptic changes}

To examine whether chronic $\mathrm{LiCl}$ treatment induced changes to synapse densities, reflecting the results obtained for spines above, we assayed for pre- and postsynaptic markers of excitatory and inhibitory synapses. To estimate the number of excitatory synapses, we quantified the density, intensity and colocalization of the presynaptic vesicular glutamate transporter 1 (VGLUT1) and postsynaptic density protein 95 (PSD-95; Figure 3A and C). The density of PSD-95 puncta was significantly reduced by chronic $\mathrm{LiCl}$ treatment (control $18.9 \pm 1.5$ puncta $/ 10 \mu$ m versus chronic $\mathrm{LiCl} 12.9 \pm$ 0.9 puncta $/ 10 \mu \mathrm{m} ; p=0.0015)$, in agreement with the reduced protrusion density and number of mature spines in neurons treated with chronic $\mathrm{LiCl}$ (Figure $3 \mathrm{~A}$ and $\mathrm{C}$ ). We also found significantly fewer VGLUT1/PSD-95 co-clusters in neurons that received chronic $\mathrm{LiCl}$ treatment (control 5.9 \pm 0.5 co-clusters $/ 10 \mu \mathrm{m}$ versus chronic $\mathrm{LiCl} 4.5 \pm 0.4 \mathrm{co}-$ clusters $/ 10 \mu \mathrm{m} ; p=0.0200$; Figure $3 \mathrm{C}$ ), indicative of reduced excitatory synapse numbers after chronic $\mathrm{LiCl}$ treatment. VGLUT1 (and VGAT, see below) puncta intensity was increased in remaining chronic LiCl-treated clusters (Appendix 1, Figure S2B and C; VGLUT1: control $10.97 \pm 0.3$ a.u. versus chronic $\mathrm{LiCl} 13.41 \pm 0.5$ a.u.; VGAT: control $12.91 \pm$ 0.4 a.u. versus $\mathrm{LiCl} 17.07 \pm 0.6$ a.u.). Conversely, PSD-95 puncta intensity was reduced in cultures that received chronic $\mathrm{LiCl}$ treatment (control $6.99 \pm 0.4$ a.u. versus chronic $\mathrm{LiCl} 5.67 \pm 0.2$ a.u.; Figure 3E). Cluster intensity for PSD-95 is related to cluster size in postsynaptic spines, and this supports the reduction we observed in the percentage of large mushroom-like spines and the trend for reduced mean head diameter of mature spines seen above. We also quantified puncta density and colocalization of the inhibitory presynaptic vesicular $\gamma$-aminobutyric acid (GABA) transporter (VGAT) and postsynaptic GABA receptor scaffold gephyrin (Figure 3B and D). We observed a significant increase in the density of gephyrin puncta (control $7.34 \pm 0.5$ gephyrin puncta $/ 10 \mu \mathrm{m}$ versus chronic $\mathrm{LiCl} 11.56 \pm 1.4$ gephyrin puncta $/ 10 \mu \mathrm{m} ; p=0.0354$ ) and in VGAT/gephyrin co-clusters 
A

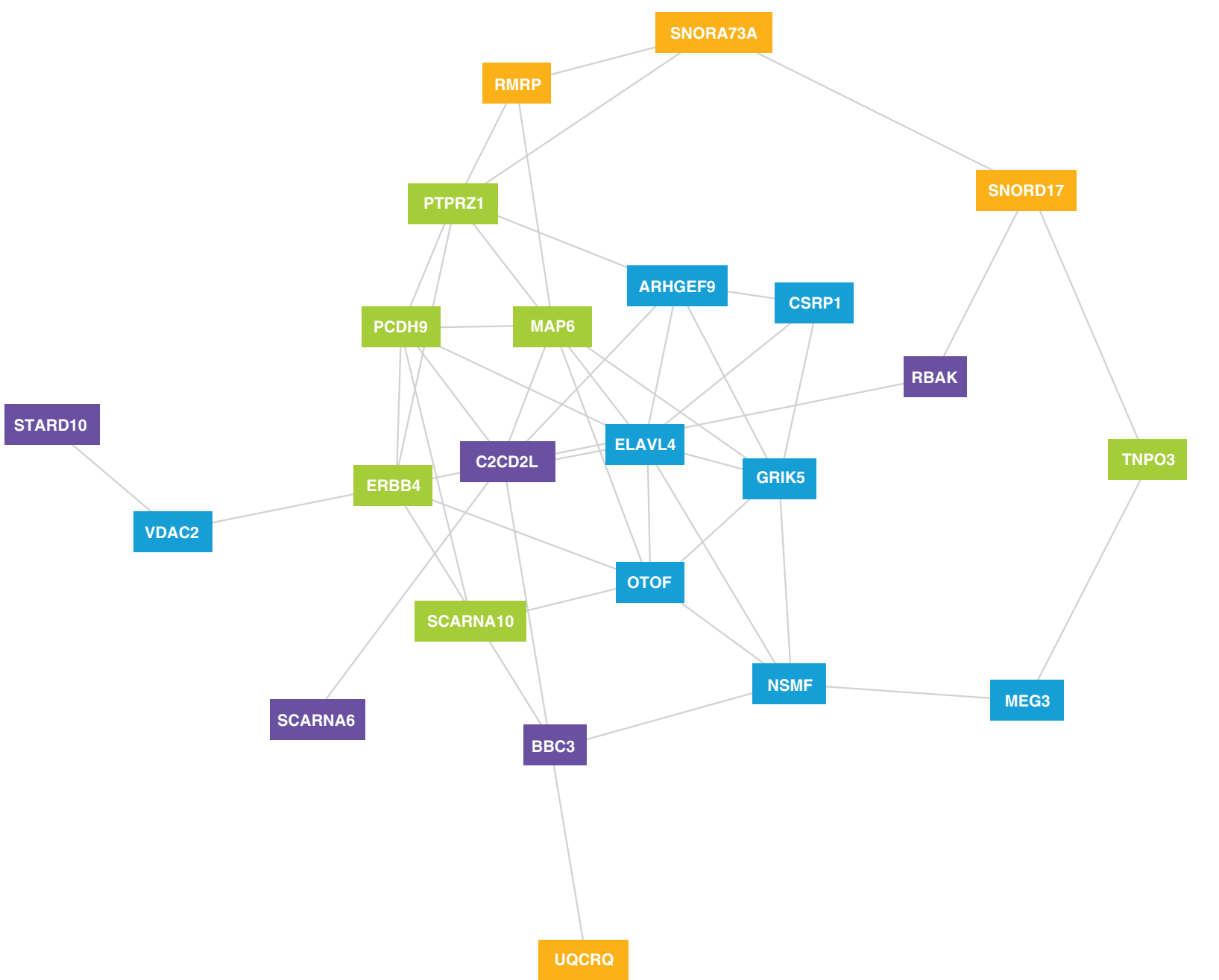

B

\begin{tabular}{l|l} 
Pathway & $\boldsymbol{p}$ value \\
\hline Trafficking of AMPA receptors & 0.000096800 \\
\hline Glutamate binding, activation of AMPA receptors and synaptic activity & 0.000096800 \\
\hline Calcium ion binding & 0.000490000 \\
\hline CREB phosphorylation through the activation of CaMKII & 0.000246660 \\
\hline Ras activation upon calcium ion influx through NMDA receptor & 0.000284473 \\
\hline tRNA processing in the nucleus & 0.000730176 \\
\hline SUMOylation of DNA replication proteins & 0.000929913 \\
\hline Transmission across chemical synapses & 0.000990993 \\
\hline
\end{tabular}

Fig. 1: Chronic lithium treatment alters gene expression in mouse cortical neurons. (A) Clustering of differentially expressed genes at 18 days in vitro in primary cortical mouse neurons treated chronically with lithium ( $\mathrm{LiCl} 1.5 \mathrm{mM}$ ) for 7 days compared to controls. Each gene cluster is identified by a colour. (B) Significant pathways of gene clusters identified through gene network analysis for the effect of chronic lithium treatment on primary cortical mouse neurons. 


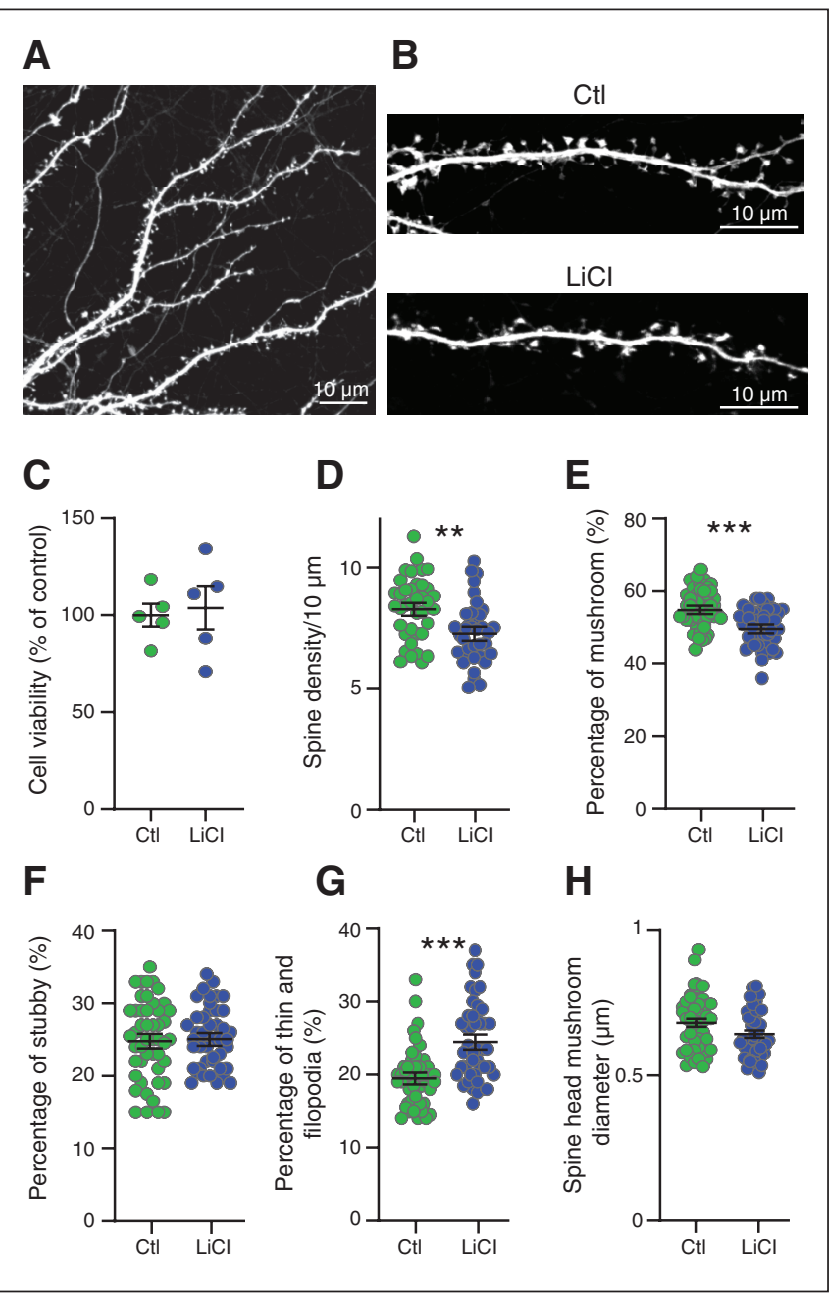

Fig. 2: Chronic lithium treatment led to changes in spine morphology. (A) Representative confocal image of dendrites expressing free GFP. Bar $10 \mu \mathrm{m}$. (B) Enlargement of a dendrite expressing free GFP, treated with lithium $(\mathrm{LiCl} 1.5 \mathrm{mM})$ for 7 days or not treated $(\mathrm{Ctl})$. Bar $10 \mu \mathrm{m}$. (C) Cell viability tests showed no toxic effect of lithium $(1.5 \mathrm{mM})$ on neurons treated for 7 days, from 5 independent experiments. Scatter plots show (D) the density of protrusions and the relative proportion of (E) mushroom spines, $(F)$ stubby spines and $(G)$ thin spines in neurons treated with lithium for 7 days or not treated $(\mathrm{Ctl})$. $(\mathrm{H})$ Scatter plots show the spine head mushroom diameter from neurons treated with lithium or not treated $(\mathrm{Ctl})$. Data shown in $\mathrm{C}$ to $\mathrm{H}$ are mean \pm standard error of the mean. Statistical significance was determined using parametric unpaired $t$ tests for $\mathrm{C}$ to $\mathrm{G}$ and nonparametric Mann-Whitney tests for $\mathrm{H} ; n=\sim 5000$ protrusions per condition from $\sim 45$ neurons from 4 independent experiments. ${ }^{* *} p=0.0013 ;{ }^{* * *} p<0.0005$. Ctl $=$ control; GFP = green fluourescent protein; $\mathrm{LiCl}=$ lithium chloride.

$(1.87 \pm 0.09$ co-clusters $/ 10 \mu \mathrm{m}$ versus chronic $\mathrm{LiCl} 2.58 \pm 0.2$ co-clusters $/ 10 \mu \mathrm{m} ; p=0.0105)$ in neurons that received chronic $\mathrm{LiCl}$ treatment control (Figure 3D). Gephyrin puncta intensity was unchanged, but VGAT puncta density was increased in neurons that received chronic $\mathrm{LiCl}$ treatment (Appendix 1, Figure S2A and B). The data indicate that lithium treatment increased the number of inhibitory synapses.
To further assess the reduction in the number of excitatory synapses (Figure 3C) induced by chronic $\mathrm{LiCl}$ treatment and to determine whether other synaptic changes were occurring, we measured protein levels of PSD-95, GluA1 and GluA2 AMPA receptor subunits by Western blot analysis (Figure 3F and $G$ ). We found that GluA1 protein expression was unchanged, but GluA2 and PSD-95 expression was significantly reduced in response to chronic $\mathrm{LiCl}$ (GluA2 $-13.8 \%$ of controls and PSD-95 -16.9\% of controls; Figure 3G). These findings suggest that chronic $\mathrm{LiCl}$ treatment downregulates GluA2-containing AMPA receptors and the number of excitatory synapses. Interestingly, these results were accentuated by a higher dose of chronic $\mathrm{LiCl}$ (3.5 mM; GluA2 $-54.42 \%$ of controls and PSD-95 $-54.49 \%$ of controls; Appendix 1, Figure S2D). Notably, the expression levels of AMPA receptors and PSD-95 were unchanged when neurons were treated acutely for $4 \mathrm{~h}$ (1.5 mM; Appendix 1, Figure S2E), suggesting that longer time is needed for $\mathrm{LiCl}$ to alter the levels of these proteins. The expression levels of synapsin 1 and gephyrin were unchanged by chronic or acute $\mathrm{LiCl}$ treatment $(1.5 \mathrm{mM}$; Figure 3G and Appendix 1, Figure S2D and E).

\section{Lithium decreased neuronal excitability and excitatory synaptic transmission, and increased inhibitory synaptic transmission}

To examine the functional consequence of lithium treatment on neuronal networks, we assessed intrinsic membrane excitability and action potential generation, in addition to quantification of excitatory and inhibitory synaptic transmission. To assess neuronal excitability, we recorded membrane deflection in response to current injection (Appendix 1, Figure S3B) and action potential firing induced by depolarizing currents in current clamps. Although the results were highly variable, neurons that received chronic $\mathrm{LiCl}$ treatment appeared to fire fewer action potentials than control neurons (Figure $4 \mathrm{~A}$ to $\mathrm{C}$ and Appendix 1, Figure S3A), indicating that chronic $\mathrm{LiCl}$ reduced cell excitability. We then assayed sodium and potassium currents in voltage clamps and found that both were reduced in neurons that received chronic $\mathrm{LiCl}$ treatment. Specifically, the peak sodium current in neurons that received chronic $\mathrm{LiCl}$ treatment was $-16.3 \%$ compared to controls (control $4.97 \pm 0.3 \mathrm{pA}$ versus chronic $\mathrm{LiCl} 4.16 \pm 0.3 \mathrm{pA}$; Figure $4 \mathrm{D}$ and $\mathrm{E}$ ), and slow and fast potassium currents were $-19.3 \%$ and $-12.13 \%$ compared to controls (slow potassium current: control $2.6 \pm 0.15 \mathrm{pA}$ versus chronic $\mathrm{LiCl} 2.1 \pm$ $0.13 \mathrm{pA}$; fast potassium current: control $3.3 \pm 0.19 \mathrm{pA}$ versus chronic $\mathrm{LiCl} 2.9 \pm 0.16 \mathrm{pA}$; Figure $4 \mathrm{~F}$ to $\mathrm{H}$ and Appendix 1, Figure S3C) These data demonstrate that chronic $\mathrm{LiCl}$ treatment alters sodium and potassium channel conductance and decreases membrane excitability.

We assessed synaptic network activity by recording quanta of AMPA receptor-mediated miniature excitatory postsynaptic currents (mEPSCs) and GABA receptor-mediated miniature inhibitory postsynaptic currents (mIPSCs) with voltageclamp recording (Figure $4 \mathrm{I}$ and $\mathrm{K}$ ). In neurons that received chronic $\mathrm{LiCl}$ treatment, the mEPSC event amplitude was increased by $27 \%$ compared to control neurons (control $29.67 \pm$ 


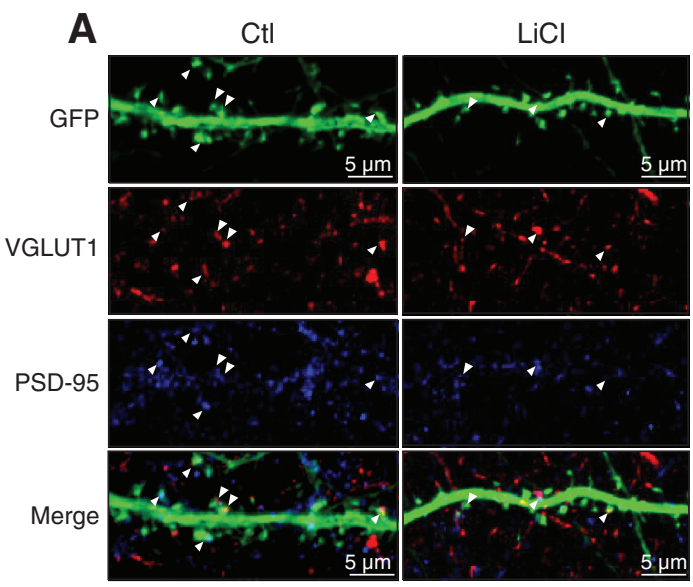

B
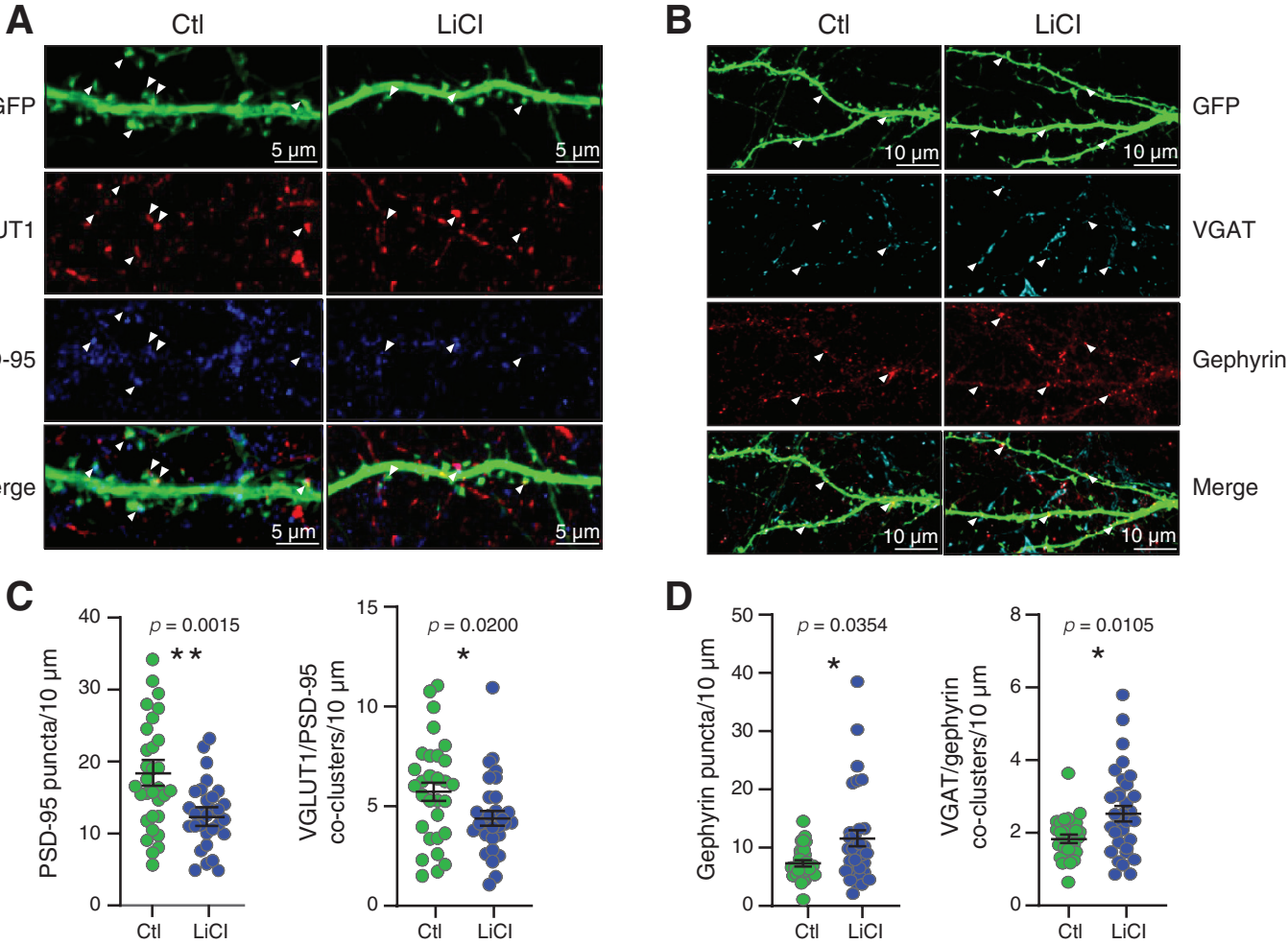

D

E

\section{F}
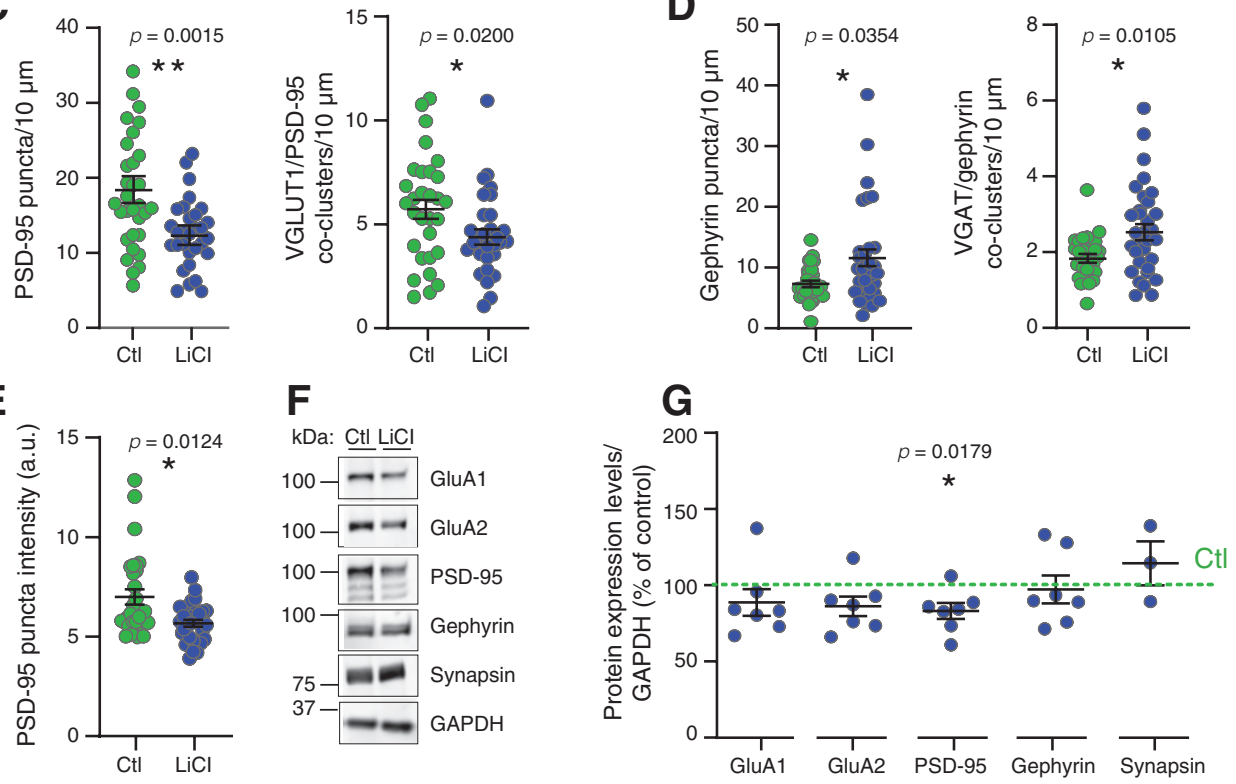

Fig. 3: Chronic lithium treatment induced excitatory and inhibitory synaptic changes. (A) Representative confocal image of dendrites expressing free GFP from neurons treated with lithium ( $\mathrm{LiCl} 1.5 \mathrm{mM}$ ) for 7 days or not treated (Ctl), with antibodies directed against VGAT and gephyrin. Arrowheads show the VGAT and gephyrin puncta localization and the colocalization between VGAT and gephyrin in the merge, indicating the inhibitory synapses. Bar $10 \mu \mathrm{m}$. (B) Scatter plots show quantification of gephyrin puncta density/10 $\mu \mathrm{m}$ and VGAT/gephyrin co-cluster density representing the density of inhibitory synapses per $10 \mu \mathrm{m}$ from secondary or tertiary dendrites from neurons that were treated with lithium ( $\mathrm{LiCl} 1.5 \mathrm{mM}$ ) for 7 days or not treated (Ctl); $n=32$ neurons per condition from 3 separate experiments. (C) Representative confocal image of dendrites expressing free GFP from neurons treated with lithium ( $\mathrm{LiCl} 1.5 \mathrm{mM})$ for 7 days or not treated (Ctl), with antibodies directed against VGLUT1 and PSD-95. Arrowheads show the VGLUT1 and PSD-95 puncta localization and the colocalization between VGLUT1 and PSD-95 in the merge, indicating the excitatory synapses. Bar $5 \mu \mathrm{m}$. (D) Scatter plots show quantification of PSD-95 puncta density/10 $\mu \mathrm{m}$ and VGLUT1/PSD-95 co-cluster density representing the density of excitatory synapses per $10 \mu \mathrm{m}$ from secondary and tertiary dendrites, as well as (E) PSD-95 puncta intensity from neurons treated with lithium ( $\mathrm{LiCl} 1.5 \mathrm{mM}$ ) for 7 days or not treated (Ctl); $n=30$ neurons per condition from 3 separate experiments. Data shown in $B$ to $E$ are mean \pm standard error of the mean. Statistical significance was determined using a nonparametric Mann-Whitney test. (F) Representative immunoblots for GluA1, GluA2, PSD-95, gephyrin, synapsin1 and GAPDH of neuronal extract (18 days in vitro) from neurons treated with lithium ( $\mathrm{LiCl} 1.5 \mathrm{mM}$ ) for 7 days or not treated (Ctl). (G) Quantification with scatter plot of some pre- and postsynaptic protein expression levels normalized with GAPDH (represented as percent of control) of neuronal extract (18 days in vitro) from neurons treated with lithium $(\mathrm{LiCl} 1.5 \mathrm{mM})$ for 7 days or not treated (Ctl) from 3 to 7 separate experiments. Data are mean \pm standard error of the mean. Statistical significance was determined using a 1-sample $t$ test with a hypothetical value of 100 for controls. Ctl $=$ control; GAPDH = glyceraldehyde 3-phosphate dehydrogenase; GFP = green fluourescent protein; LiCl = lithium chloride; VGAT = vesicular $\gamma$-aminobutyric acid transporter; VGLUT1 = vesicular glutamate transporter 1. 
$1.5 \mathrm{pA}$ versus chronic $\mathrm{LiCl} 37.71 \pm 1.9 \mathrm{pA})$ and event frequency was decreased by $47 \%$ (control $12.44 \pm 1.4 \mathrm{~Hz}$ versus chronic LiCl $6.5 \pm 1 \mathrm{~Hz}$; Figure 2J and Appendix 1, Figure S4A and B); we observed no changes in event decay tau (Figure 4J). Event amplitude was not different for mIPSCs (control 23.46 $\pm 1.8 \mathrm{pA}$ versus chronic $\mathrm{LiCl} 24.25 \pm 1.9 \mathrm{pA}$ ), but we did observe a significant increase in MIPSC event frequency in neurons that received chronic $\mathrm{LiCl}$ treatment (control $3.3 \pm$ $0.35 \mathrm{~Hz}$ versus chronic $\mathrm{LiCl} 4.8 \pm 0.53 \mathrm{~Hz}$; Figure $4 \mathrm{~L}$ and Appendix 1, Figure S4D and E); again, we found no change in event decay tau (Figure $4 \mathrm{~L}$ ). Measures of the membrane properties of voltage-clamp recordings can be found in Appendix 1, Figure S4C and F. Together, the electrophysiological experiments demonstrated that chronic $\mathrm{LiCl}$ treatment altered synaptic network properties by decreasing excitatory activity and increasing inhibitory activity.

\section{Chronic lithium treatment downregulated $m$ GluR-mediated calcium response and signalling}

Because chronic $\mathrm{LiCl}$ treatment downregulated the major depolarizing AMPA receptor current at glutamatergic synapses, it was of interest to determine which regulatory signal transduction pathways were altered, and whether any changes in these were a consequence or cause of altered synaptic transmission. To this end, we investigated ionotropic and metabotropic glutamate receptor-mediated calcium signalling in cultures acutely or chronically treated with $\mathrm{LiCl}$. We conducted ratiometric calcium imaging to measure intracellular calcium levels and flux upon stimulation. We added tetrodotoxin to block sodium channels and action potential burst firing, so calcium flux was directly in response to glutamate receptor activation. Intracellular calcium levels at rest were similar for the chronic LiCl-treated and control neurons (Appendix 1, Figure S5A). Control neurons were first exposed to repeated glutamate pulses, which did not attenuate calcium $\left(\mathrm{Ca}^{2+}\right)$ flux upon repeated applications (Appendix 1, Figure S5B). Then, after exposure to $1 \mu \mathrm{M}$ glutamate, we applied an acute $\mathrm{LiCl}$ treatment (5 $\mathrm{min}, 1.5 \mathrm{mM}$ ) before repeated glutamate stimulations. The second calcium response was similar to the first, indicating that $\mathrm{LiCl}$ did not directly reduce glutamate-induced $\mathrm{Ca}^{2+}$ flux or act as an antagonist of glutamate receptors (Figure 5A). The use of specific agonists of NMDA (Figure 5B) and mGluR5 (Figure 5C) showed that acute $\mathrm{LiCl}$ treatment had no differential effect on either NMDA- or mGluR5mediated $\mathrm{Ca}^{2+}$ responses (Figure 5B and C). Similarly, medium-term $\mathrm{LiCl}$ treatment for $4 \mathrm{~h}$ did not alter glutamate-induced $\mathrm{Ca}^{2+}$ flux (Appendix 1, Figure S5C).

In contrast to acute application, glutamate stimulation of neurons that were treated with chronic $\mathrm{LiCl}(7 \mathrm{~d})$ led to a significant decrease in $\mathrm{Ca}^{2+}$ response amplitude (chronic $\mathrm{LiCl} \Delta \mathrm{F}=73.9 \%$ of control; $p=0.0001$ Figure 5D). The $\mathrm{Ca}^{2+}$ response amplitude upon specific activation of NMDA receptors was unchanged, indicating that chronic $\mathrm{LiCl}$ treatment did not affect NMDA receptor-mediated $\mathrm{Ca}^{2+}$ responses (Figure 5E). Conversely, chronic LiCl treatment significantly reduced the $\mathrm{Ca}^{2+}$ response amplitude pro- duced by direct stimulation of mGluR5 (by 3,5-dihydroxyphenylglycine [DHPG] agonism; chronic $\mathrm{LiCl} \Delta \mathrm{F}=70.8 \%$ of control; Figure 5F). The data suggest that chronic $\mathrm{LiCl}$ exposure specifically reduced $\mathrm{Ca}^{2+}$ release from the endoplasmic reticulum. This attenuation of $\mathrm{Ca}^{2+}$ responses to glutamate and DHPG stimulation could have been due to impaired receptor activation (e.g., a reduction in the number or sensitivity of mGluR5 receptors at the cell surface or IP3 receptors on the endoplasmic reticulum). Alternatively, lithium might affect the mGluR5-PLC-PIP2-DAG-IP3 signalling cascade (i.e., through altered PLC activation, PIP2 hydrolysis or diacylglycerol [DAG] and IP3 availability in the cell). We found that mGluR5 and PLC $\beta 1$ expression levels were unchanged by chronic $\mathrm{LiCl}$ (Appendix 1, Figure S6B), suggesting that lithium might affect the cycling of IP3 signalling rather than the levels of associated proteins. Either possibility would result in reduced calcium release in the endoplasmic reticulum.

To determine whether attenuation of glutamate-mediated $\mathrm{Ca}^{2+}$ responses induced by chronic $\mathrm{LiCl}$ treatment affects downstream signalling pathways, we assayed PKC, a major downstream target of mGluR5 activation; PKC is responsible for regulating a wide range of neuronal functions, such as excitability, neurotransmission and plasticity. ${ }^{35-39}$ The PKC $\gamma$ isoform is expressed exclusively in the brain, and its activity is regulated by phosphorylation at threonine 514 (phPKC $\gamma$ ). The levels of phPKC $\gamma$ measured by Western blot analysis from neurons treated with 2,5 and $10 \mathrm{mM}$ of $\mathrm{LiCl}$ for $4 \mathrm{~h}$ were similar to controls (Figure 5G). The increase of phPKC $\gamma$ levels (not significant) with $10 \mathrm{mM}$ of $\mathrm{LiCl}$ could have been due to lithium toxicity effects, because this dose was 10 times higher than the therapeutic dose. However, phPKC $\gamma$ levels were reduced after chronic $\mathrm{LiCl}$ treatment $(1.5 \mathrm{mM}$; a reduction of $25.6 \%$; Figure $5 \mathrm{G}$ ). Our data demonstrate that $\mathrm{PKC} \gamma$ activity is not directly affected by $\mathrm{LiCl}$, but is a consequence of prolonged exposure.

A second major downstream effector of mGluR5 stimulation is GSK3 $\beta$, a kinase involved in several neuronal processes such as cytoskeletal reorganization and neuroplasticity. ${ }^{40}$ Phosphorylation of GSK3 $\beta$ at the serine 9 residue (phGSK3 $\beta$ ) inhibited GSK3 $\beta$ kinase activity. In contrast to the effects on $\mathrm{PKC}, 4 \mathrm{~h} \mathrm{LiCl}$ treatment with increasing concentrations $(2,5$ and $10 \mathrm{mM})$ and chronic $\mathrm{LiCl}$ treatment both significantly increased phGSK3 $\beta$ in a dose-dependent manner (Figure $5 \mathrm{H}$ ). These results demonstrated that $\mathrm{LiCl}$ has a rapid and likely direct effect on GSK3 $\beta$ kinase activity ( $\mathrm{LiCl} 2 \mathrm{mM}$ $187 \%$ of controls; LiCl 5 mM 166\% of controls; LiCl $10 \mathrm{mM}$ $169 \%$ of controls; chronic $\mathrm{LiCl} 1.5 \mathrm{mM} 136 \%$ of controls).

\section{Discussion}

In this study, we provide the first holistic report of chronic lithium treatment decreasing the balance of excitatory to inhibitory synaptic transmission in cortical neuron networks. This effect correlated with and may be a result of altered intracellular calcium signal transduction, expressed by changes to the number and function of excitatory and inhibitory synaptic connections. 

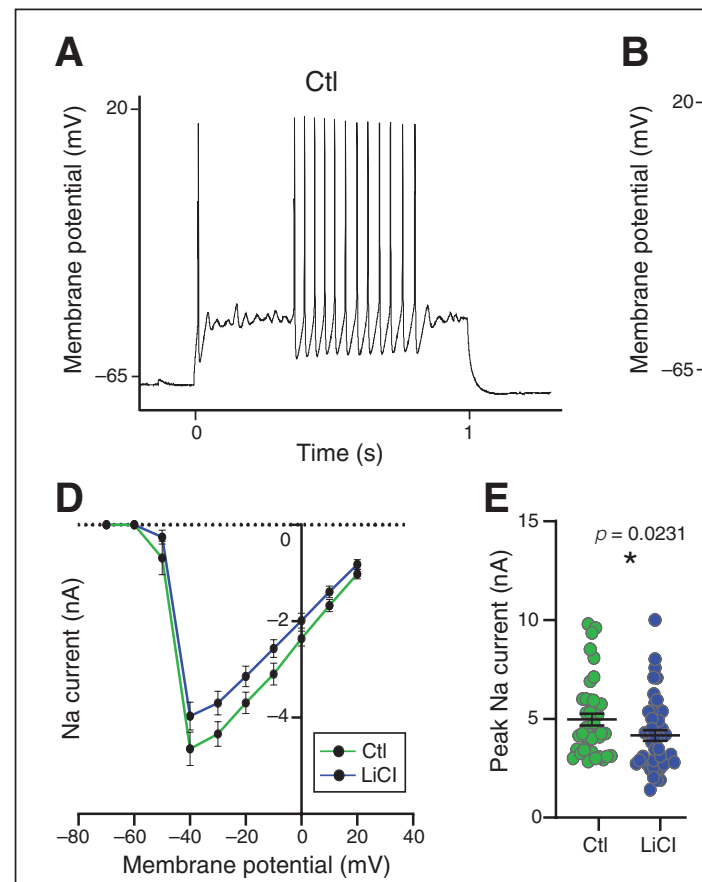

I

Ctl

mEPSCs
B

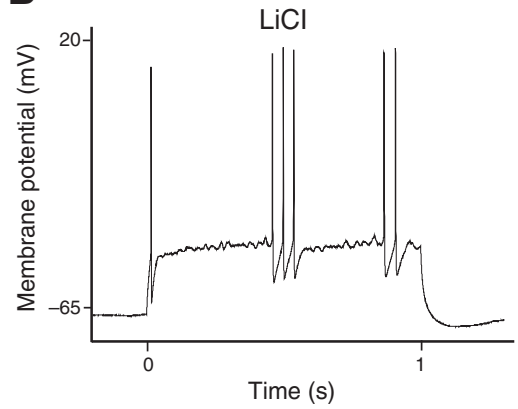

F

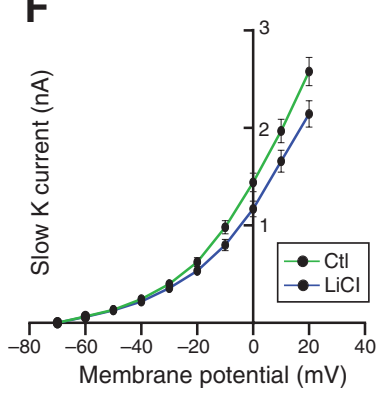

C

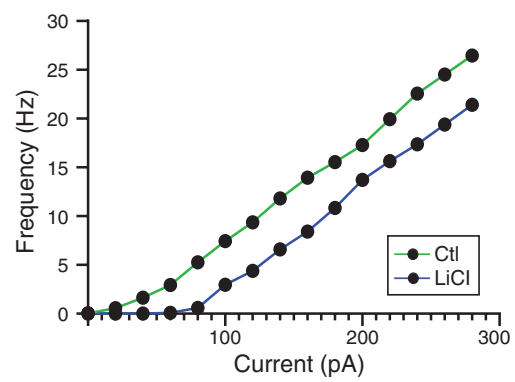

G



$\mathbf{H}$

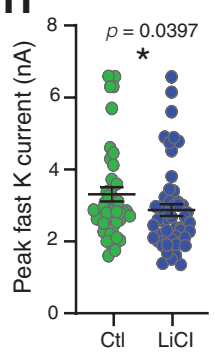

K mIPSCs

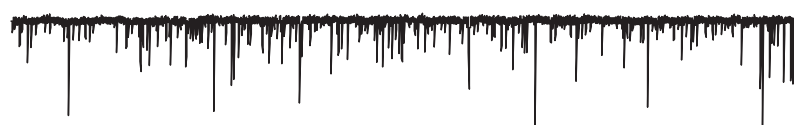
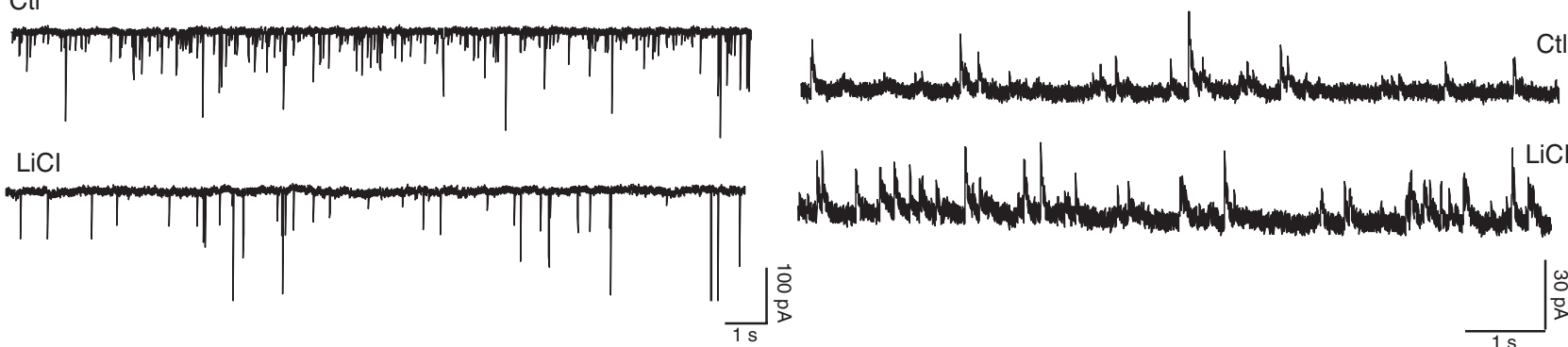

J

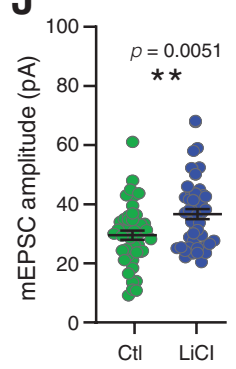

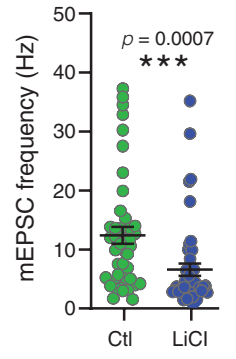
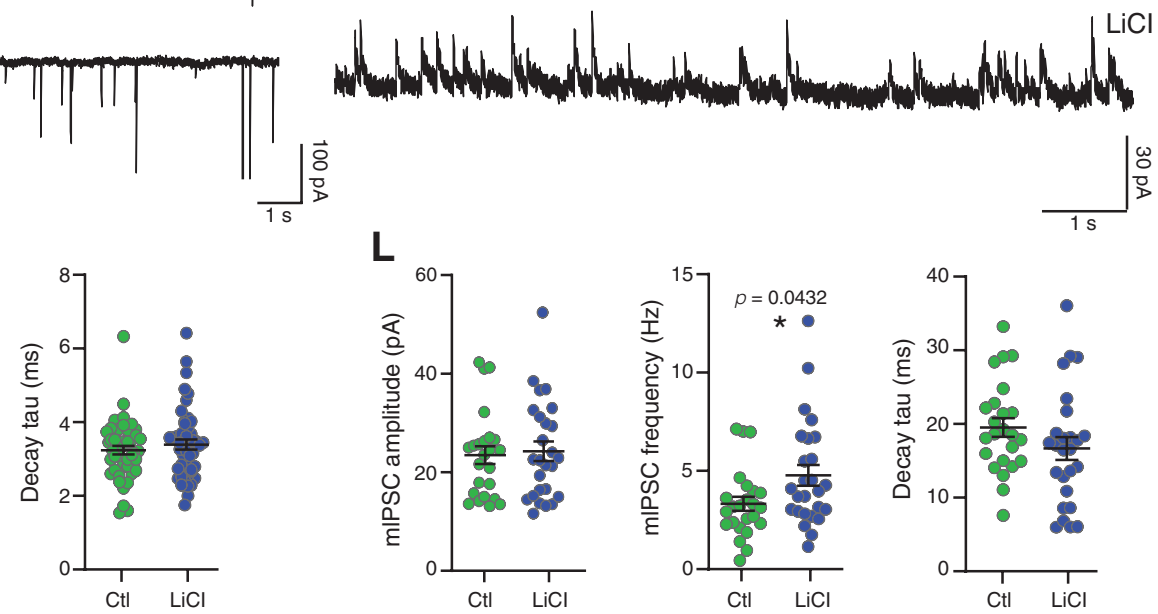

Fig. 4: Chronic lithium treatment reduced neuronal excitability and excitatory transmission, and it increased inhibitory synaptic transmission. Representative action potential trains in (A) control and (B) chronically treated ( $\mathrm{LiCl} 1.5 \mathrm{mM}$ ) neurons at 18 days in vitro, in response to a $1 \mathrm{~s}$ depolarizing $120 \mathrm{pA}$ current step from approximately $-65 \mathrm{mV}$. (C) Frequency-current plot among repetitively firing neurons. Frequency represents the mean number of spikes per second from approximately 32 neurons per condition from 4 independent experiments. (D) Voltage dependence of the amplitude of the sodium current. (E) Quantification of the peak amplitude of sodium currents in neurons treated with lithium ( $\mathrm{LiCl} 1.5 \mathrm{mM}$ ) for 7 days or not treated (Ctl). (F) Voltage dependence of the amplitude of the slow potassium current. $(\mathrm{G}$ and $\mathrm{H})$ Quantification of the peak amplitude of the slow and fast potassium currents in neurons treated with lithium $(\mathrm{LiCl} 1.5 \mathrm{mM})$ for 7 days or not treated (Ctl). The data from $\mathrm{D}$ to $\mathrm{H}$ are from 5 separate experiments and are mean \pm standard error of the mean. Statistical significance was determined by nonparametric Mann-Whitney tests. (I) Representative sample traces of mEPSCs from neurons treated with lithium ( $\mathrm{LiCl} 1.5 \mathrm{mM}$ ) for 7 days or not treated (Ctl). Scale bar shown as inset. (J) Scatter plots show quantification of amplitude, frequency and decay tau for mEPSCs of approximately 45 neurons from 4 independent experiments. (K) Representative sample traces of mIPSCs from neurons treated or not with $\mathrm{LiCl}(1.5 \mathrm{mM})$ for 7 days. Scale bar shown as inset. (L) Scatter plots show quantification of amplitude, frequency and decay tau for mIPSCs of approximately 26 neurons from 3 independent experiments. Data from $\mathrm{J}$ and $\mathrm{L}$ are mean \pm standard error of the mean. Statistical significance was determined by nonparametric Mann-Whitney tests. Ctl $=$ control; $\mathrm{LiCl}=$ lithium chloride; $\mathrm{mEPSC}=$ miniature excitatory postsynaptic current; $\mathrm{mIPSC}=$ miniature inhibitory postsynaptic current. 

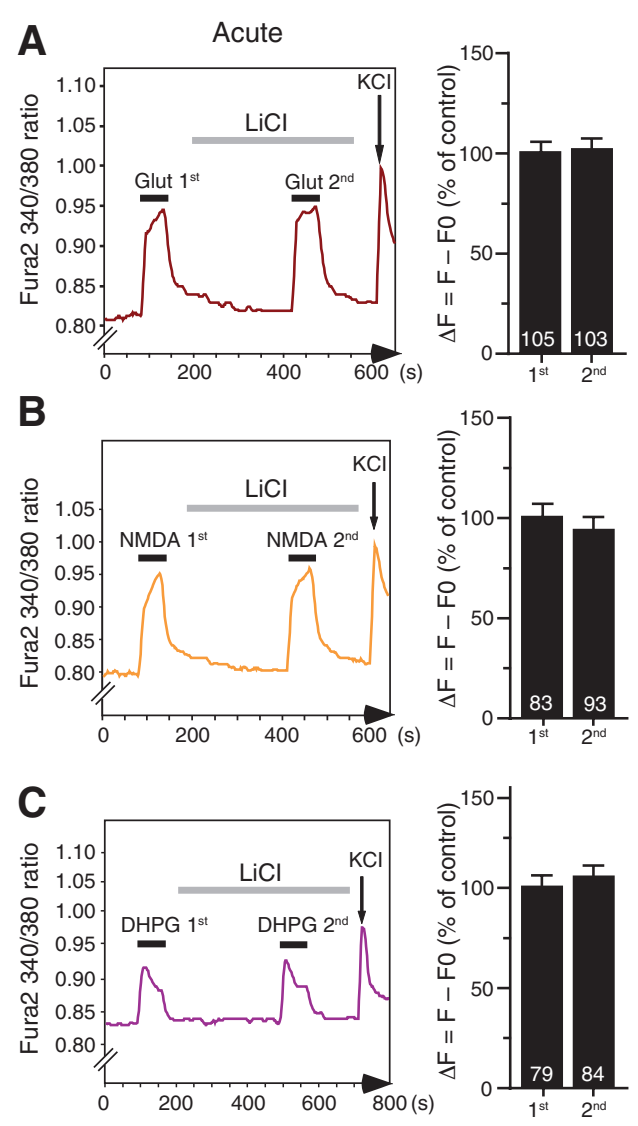

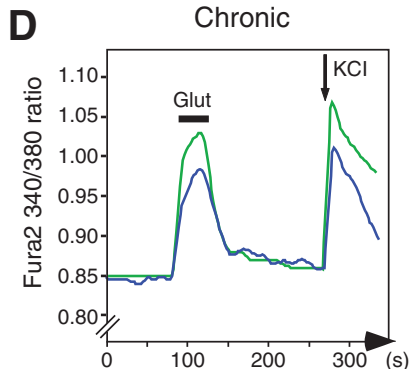

E

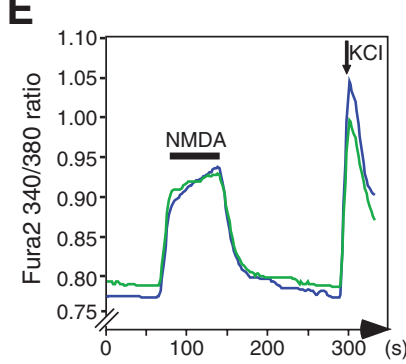

F

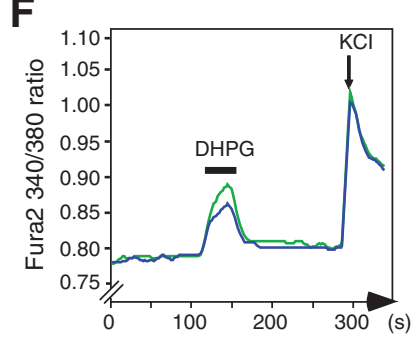

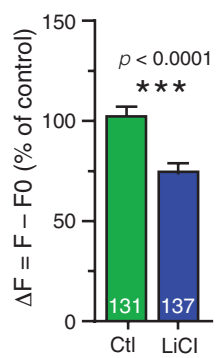
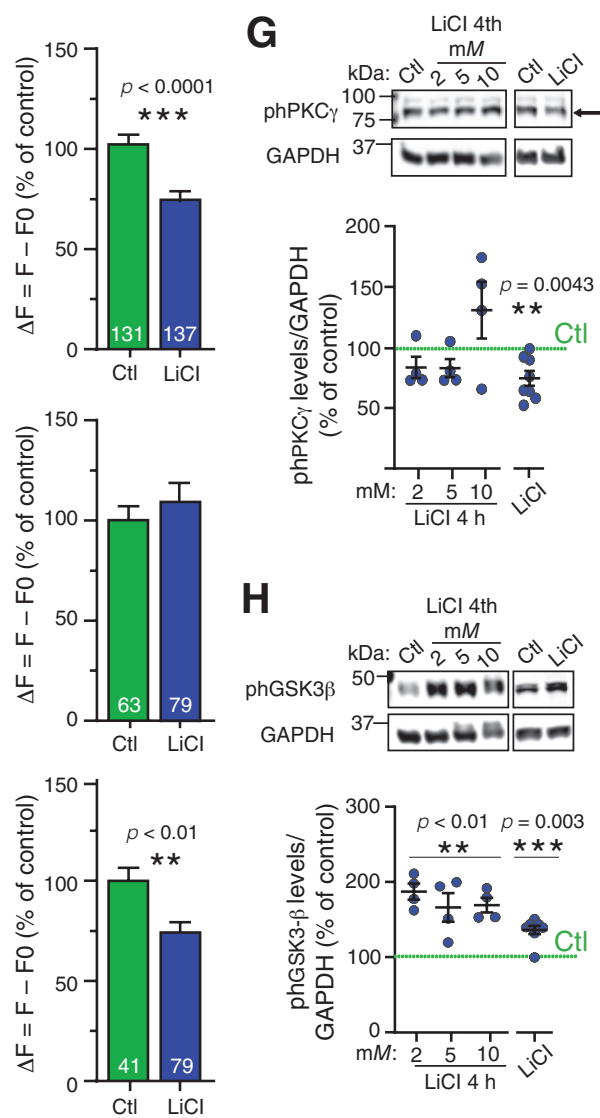

Fig. 5: Chronic lithium treatment reduced mGluR-mediated calcium response and signalling. (A to C) Representative sample traces of calcium responses after glutamate $(1 \mu M)$, NMDA $(10 \mu M)$ and DHPG $(100 \mu M)$ stimulation; histograms show the quantification of calcium changes upon stimulation in mouse primary cortical neurons. The second stimulations were preceded by acute lithium (LiCl $1.5 \mathrm{mM}$ ) treatment for $5 \mathrm{~min}$, followed by $2 \mathrm{~s}$ of $\mathrm{KCl}$ stimulation. ( $\mathrm{D}$ to $\mathrm{F}$ ) Representative sample traces of calcium responses after glutamate (1 $\mu M$ ), NMDA $(10 \mu M)$ and DHPG $(100 \mu M)$ stimulation; histograms show the quantification of calcium changes as percent of control upon drug stimulation in mouse primary cortical neurons chronically treated with lithium ( $\mathrm{LiCl} 1.5 \mathrm{mM}$ ) for 7 days or not treated (Ctl). The number of neurons is indicated on each histogram from 3 independent experiments. Data shown in A to $F$ are mean \pm standard error of the mean. Statistical significance was determined by paired $t$ tests for acute treatments (A to $C$ ) and unpaired $t$ tests for chronic treatment (D to $F$ ). (G and H) Representative immunoblots and quantification of antiphosphorylated levels of PKC $\gamma$ (threnonine 514) and GSK3ß (serine 9) normalized with GAPDH and represented as percent of control from neuronal extracts from mouse primary cortical neurons treated acutely with 2,5 and $10 \mathrm{mM}$ of $\mathrm{LiCl}$ for $4 \mathrm{~h}$, or chronically with lithium $(\mathrm{LiCl} 1.5 \mathrm{mM})$ for 7 days. The data are from 4 ( $4 \mathrm{~h}$ treatment) and 8 (chronic treatment) separate experiments and are mean \pm standard error of the mean. Statistical significance was determined by 1-sample $t$ tests with a hypothetical value of 100 for controls. Ctl = control; DHPG = 3,5-dihydroxyphenylglycine; GAPDH = glyceraldehyde 3-phosphate dehydrogenase; GSK3 $\beta$ = glycogen synthase kinase $3 \beta ; \mathrm{LiCl}=$ lithium chloride; $\mathrm{mGluR}=$ metabotropic glutamatergic receptor; NMDA = N-methyl-D-aspartate; $\mathrm{ph}=$ phosphorylated; $\mathrm{PKC}=$ protein kinase $\mathrm{C}$.

Throughout development and into adulthood, neural connectivity at synapses is subject to dynamic regulation, including the formation, maintenance and elimination of synapses themselves. Synaptic transmission is believed to be the means by which all experiences and motivations are stored and used, and synaptic plasticity (rapid, activity-dependent alterations to synaptic transmission) is the leading candidate for the cellular basis of learning and memory. In the mammalian forebrain, most excitatory synapses occur on dendritic spines, and changes to their number, morphology and activity are modelled by increases (long-term potentiation) and decreases (long-term depression) in synaptic weighting. ${ }^{41,42}$ With long- term potentiation, spines enlarge and become more mushroom-like; long-term depression is associated with spine shrinkage. Disruptions to dendritic spine shape, size or number accompany many neurodegenerative diseases, and it has been suggested that dendritic spine alterations are also the substrate of many neuropsychiatric disorders, particularly those that involve deficits in information processing, such as autism spectrum disorder and schizophrenia. ${ }^{42}$

Decreased spine density has been shown postmortem in a preliminary study of the subiculum in people with mood disorders, ${ }^{43}$ and in the prefrontal cortex of people with bipolar disorder. ${ }^{44}$ It is unclear how reduced spine density in these 
individuals might reflect a general state of the condition or a brain region-specific effect, or whether it could even be a result of successful medication. In our hands, lithium reduced measures of excitatory spine maturity and appeared to use processes similar to those employed in physiologic long-term depression, decreasing excitatory activity and the number of mature versus immature spines. The increase of mEPSC amplitude observed in the present study in neurons treated with chronic $\mathrm{LiCl}$ could reflect an increase in the immature spines phenotype, as suggested in previous studies. ${ }^{45-47}$

In support of our results, chronic lithium treatment reduced spine density in a Fragile $X$ mouse model. ${ }^{32}$ However, spine density increased with acute lithium treatment in a DIXDC1 knockout mouse model of depression. ${ }^{33}$ It may be that lithium generally facilitates network rearrangements and normalizes spine dysfunction in whichever direction is required, but further investigations may provide consensus on which direction and over what time frame changes usually occur. It has also been proposed that lithium rescues spine pathology in bipolar disorder by reducing phosphorylation of the cytoskeleton regulator collapsing response mediator protein-2 (CRPM2); ${ }^{34}$ in rat hippocampal cultures, chronic treatment with a dose 2 times higher than we used in our study resulted in enlarged spines and increased spine density. We found that chronic lithium not only reduced spine number but also decreased the percentage of mature spines, mature spine width and PSD-95 puncta intensity. These discrepancies may have been due to the higher dose and/or different responses between rat hippocampus and mouse cortex. More studies will be required to settle this discrepancy.

Several rodent models of mania have been generated that have traditionally relied on pharmacological (e.g., psychostimulant amphetamine-induced) or environmental (sleep deprivation-induced) stresses to induce mania-like states, and more recently several transgenic mice have been developed. ${ }^{48,49}$ A recent study using knock-in mice of the Ank3 W1989R, ${ }^{50}$ a variant reported as carried by a bipolar disorder family (and found in approximately 1:10000 European Americans), ${ }^{51}$ showed a reduction in MIPSC and an increase in mEPSC frequency, leading to neuronal hyperexcitability. If this is the case in untreated lithium-responsive patients, then our finding that chronic lithium treatment has the opposite effect may explain its therapeutic effect. This could also explain the efficacy of lithium in bipolar disorder Ank3 mutation carriers. ${ }^{50}$ Elsewhere, Yang and colleagues ${ }^{52}$ generated forebrain-specific PLC $\gamma 1$ knockout mice that exhibited maniclike behaviour and cognitive deficits associated with a significant reduction in mIPSC frequency. In the present study, we showed that chronic lithium treatment promoted inhibitory transmission and increased gephyrin clusters at inhibitory synapses. Together, these studies suggest that manic phases correspond to an increased excitatory-inhibitory synaptic ratio. Our results were in line with other studies ${ }^{53,54}$ indicating that chronic lithium treatment can counteract abnormalities in excitatory-inhibitory circuit balance observed in the mania state in bipolar disorder animal models, by rearranging the number, morphology and function of excitatory and inhibitory synapses in a manner that favours inhibition. On this note, lithium has also been shown to reduce synaptic AMPA receptor expression, ${ }^{55-57}$ again consistent with the reduction in excitatory synapse numbers observed here.

An important aspect of our results is the demonstration that the chronic effects of lithium are distinct from the acute effects. Specifically, lithium treatment from $5 \mathrm{~min}$ to $4 \mathrm{~h}$ did not affect glutamate-mediated $\mathrm{Ca}^{2+}$ responses, demonstrating that lithium did not act as an antagonist of glutamate receptor transmission in our hands. Conversely, mGluR5 glutamate receptor-mediated $\mathrm{Ca}^{2+}$ signalling (but not total depolarizationinduced $\mathrm{Ca}^{2+}$ flux; Appendix 1, Figure S6) was specifically reduced in neurons chronically treated with $\mathrm{LiCl}$, suggesting that time is required for lithium to attenuate the mGluR5PIP2-IP3 pathway. However, our results showed a slight (but nonsignificant) decrease in mGluR5 and PLC $\beta 1$ total expression levels in neurons treated chronically with $\mathrm{LiCl}$. SourialBassilious and colleagues ${ }^{58}$ concluded that lithium attenuates intracellular $\mathrm{Ca}^{2+}$ levels because of the downregulation of mGluR5 expression at the plasma membrane, as well as a decrease in intracellular $\mathrm{Ca}^{2+}$ in the endoplasmic reticulum. Others have suggested that lithium inhibits inositol monophosphatase and inositol polyphosphate-1-phosphatase, in addition to the inositol transporter. ${ }^{59}$ This would affect the IP3 recycling pathway and reduce PIP2 and IP3 availability in the cell to trigger $\mathrm{Ca}^{2+}$ release from the endoplasmic reticulum. Either way, we sought to find out whether a decrease in $\mathrm{Ca}^{2+}$ signalling from the endoplasmic reticulum caused by chronic lithium treatment altered downstream effectors.

Our results demonstrated that chronic and acute lithium inhibited GSK3 $\beta$ kinase activity in a dose-dependent manner, but only chronic treatment reduced PKC $\gamma$ kinase activity. These 2 kinases are major regulators of synaptic receptor traffic and function, ${ }^{60}$ actin cytoskeleton reorganization, neuronal transmission and plasticity, as well as gene expression. ${ }^{39,40,61-63}$ This may be the primary mechanism by which lithium acts to prevent mania in bipolar disorder, in which the glutamatergic system is predicted to be overactivated ${ }^{24-26}$ and the inhibitory system downregulated. ${ }^{64,65}$ On this background, increased PKC activity and levels have been found post mortem in the frontal cortex of people with bipolar disorder. Furthermore, PKC hyperactivity has been detected in the blood of people with bipolar disorder ${ }^{66}$ and animal models of mania, in agreement with our conclusions and in support of the potential for PKC inhibitors as therapeutics for mania in bipolar disorder. ${ }^{61,67-69}$ It has been shown that lithium can reduce glutamatergic neurotransmission by slowing synaptic vesicle exocytosis. ${ }^{70}$ This may explain the increased VGLUT1 cluster intensity we saw here (Appendix 1, Fig. S2B and C). Although evidence is lacking for how lithium might alter the kinetics of the synaptic vesicle cycle, we would expect reduced GSK3 and PKC activity to affect presynaptic function. It may also be that intracellular $\mathrm{Ca}^{2+}$ signalling via presynaptic mGluR5 autoreceptors $^{71}$ is reduced, which may impair vesicular release. ${ }^{72}$

\section{Limitations}

The work here focused on lithium treatment effects on neuronal physiology and network activity in mouse primary 
cultures. This treatment, which we describe as chronic, was still short-term with respect to human clinical applications. Longer-term treatment of mice and assessment of similar readouts in whole animals may validate the conclusions derived here. Our focus was on neuronal networks in cultures that lack glia and other cell types; we do not exclude a potentially very important clinical contribution of lithium effects on other cell types (e.g., astrocytes, microglia, oligodendrocytes and those of the blood-brain barrier). Thus, it would be of interest to examine whether the mechanisms and neuronal effects of lithium observed here (in vitro) are similar in whole animals. Further, the rodent neuronal network may respond differently than one composed of human neurons.

\section{Conclusion}

The data here demonstrate that lithium dampens principal neuron excitability and the relative activity of excitatory (glutamatergic) transmission in a neural network. Both of these are predicted to be overactive in manic phases of bipolar disorder and might explain the therapeutic efficacy of lithium. This working model of lithium's mode of action may facilitate the development of lithium replacement strategies, aimed at restoring the balance of excitation and inhibition in overactive networks by mimicking the mechanistic effects of lithium while avoiding toxicity and other undesirable effects.

Recent advances in human induced pluripotent stem cell technology have provided the means by which to study an individual patient's neurons. Although stem cell approaches include some caveats, ${ }^{73,74}$ Mertens and colleagues ${ }^{75}$ recently discovered hyperexcitability in hippocampal-like neurons derived from induced pluripotent stem cells from people with bipolar disorder that was reversed by lithium treatment (in cells from lithium responders with bipolar disorder). These tools will facilitate our future studies of lithium's mode of action at the cellular and network level, in neurons from lithium responders versus nonresponders with bipolar disorder. We will also determine whether the working model we have provided here operates in human scenarios. Ongoing efforts will examine the mGluR5-PLC-IP3 intracellular $\mathrm{Ca}^{2+}$ signalling pathway in neurons from lithium responders with bipolar disorder, and the effects of lithium treatment. We hope this will facilitate development of novel diseasemodifying therapies for bipolar disorder, with the same therapeutic benefit of lithium but with fewer adverse effects.

Acknowledgements: We gratefully acknowledge the financial supports from Fonds de recherche en santé du Québec, Ellen Foundation and Killam to A.J.M, the Canadian Institutes of Health Research (CIHR) grant (\#332971 to G.A.R.), ERA PerMed grant to M.A. and G.A.R., the Healthy Brains for Healthy Lives and BettencourtSchueller fondation grants to B.C. and the RI-MUHC 2020 fellowship to L.S. We also thank the microscopy platform of the Montreal Neurological Institute (MNI) and the Molecular Tools Platform of the CERVO Brain Research Centre for providing us the AAV constructs. We would also like to thank the animal care facility of MNI and Bruno Vieira for assistance with mice handling. We also thank Dr. Simon Wing laboratory for the kind gift of reagents. G.A.R. holds a Canada Research Chair in Genetics of the Nervous System and the Wilder Penfield Chair in Neurosciences. C.L. is a recipient of the Vanier Canada Graduate Scholarship from the CIHR.
Affiliations: From the Montreal Neurological Institute, Department of Neurology \& Neurosurgery, McGill University, Montréal, Que., Canada (Khayachi, Ase, Liao, Kamesh, Kuhlmann, Dion, Séguéla Rouleau, Milnerwood); the Department of Human Genetics, McGill University, Montréal, Que., Canada (Rouleau); McGill University Health Centre Research Institute, Montréal, Que., Canada (Schorova); the Université de Paris, Institut de Psychiatrie et Neuroscience of Paris (IPNP), INSERM U1266, GHU Paris Psychiatrie et Neurosciences, Paris, France (Chaumette); the Department of Psychiatry, McGill University, Montréal Que., Canada (Chaumette); and the Department of Psychiatry, Dalhousie University, Halifax, NS, Canada (Alda).

Competing interests: None declared.

Contributors: A. Khayachi and A. Milnerwood designed the study. A. Khayachi, A. Ase, A. Kamesh, N. Kuhlmann and L. Schorova acquired the data, which A. Khayachi, A. Ase, C. Liao, B. Chaumette, P. Dion, M. Alda, P. Séguéla and G. Rouleau analyzed. A. Khayachi and A. Milnerwood wrote the article, which A. Ase, C. Liao, A. Kamesh, N. Kuhlmann, L. Schorova, B. Chaumette, P. Dion, M. Alda, P. Séguéla and G. Rouleau reviewed. All authors approved the final version to be published and can certify that no other individuals not listed as authors have made substantial contributions to the paper.

Content licence: This is an Open Access article distributed in accordance with the terms of the Creative Commons Attribution (CC BYNC-ND 4.0) licence, which permits use, distribution and reproduction in any medium, provided that the original publication is properly cited, the use is noncommercial (i.e., research or educational use), and no modifications or adaptations are made. See: https://creativecommons.org/licenses/by-nc-nd/4.0/

\section{References}

1. Angst J. The emerging epidemiology of hypomania and bipolar II disorder. J Affect Disord 1998;50:143-51.

2. Moreira ALR, Van Meter A, Genzlinger J et al. Review and metaanalysis of epidemiologic studies of adult bipolar disorder. J Clin Psychiatry 2017;78:e1259-69.

3. Vieta E, Berk M, Schulze TG et al. Bipolar disorders. Nat Rev Dis Primers 2018;4:18008.

4. Forstner AJ, Hofmann A, Maaser A et al. Genome-wide analysis implicates microRNAs and their target genes in the development of bipolar disorder. Transl Psychiatry 2015;5:e678.

5. Perlis RH, Smoller JW, Ferreira MA et al. A genomewide association study of response to lithium for prevention of recurrence in bipolar disorder. Am I Psychiatry 2009;166:718-25.

6. Stahl EA, Breen G, Forstner AJ et al. Genome-wide association study identifies 30 loci associated with bipolar disorder. Nat Genet 2019;51:793-803

7. Cipriani A, Hawton S, Stockton S et al. Lithium in the prevention of suicide in mood disorders: updated systematic review and meta-analysis. BMJ 2013;346:f3646.

8. Gitlin M. Lithium side effects and toxicity: prevalence and management strategies. Int J Bipolar Disord 2016;4:27.

9. Hayes JF, Marston L, Walters K et al. Lithium vs. valproate vs. olanzapine vs. quetiapine as maintenance monotherapy for bipolar disorder: a population-based UK cohort study using electronic health records. World Psychiatry 2016;15:53-8.

10. Miura T, Noma H, Furukawa TA et al. Comparative efficacy and tolerability of pharmacological treatments in the maintenance treatment of bipolar disorder: a systematic review and network meta-analysis. Lancet Psychiatry 2014;1:351-9.

11. Rybakowski JK. Response to lithium in bipolar disorder: clinical and genetic findings. ACS Chem Neurosci 2014;5:413-21.

12. Rybakowski JK, Chlopocka-Wozniak M, Suwalska A. The prophylactic effect of long-term lithium administration in bipolar patients entering treatment in the 1970s and 1980s. Bipolar Disord 2001;3:63-7.

13. Anand A, Nakamura K, Spielberg JM et al. Integrative analysis of lithium treatment associated effects on brain structure and peripheral gene expression reveals novel molecular insights into mechanism of action. Transl Psychiatry 2020;10:103. 
14. Malhi GS, Tainous M, Das P et al. Potential mechanisms of action of lithium in bipolar disorder. Current understanding. CNS Drugs 2013;27:135-53.

15. Hokin LE, Dixon JF, Los GV. A novel action of lithium: stimulation of glutamate release and inositol 1,4,5 trisphosphate accumulation via activation of the $\mathrm{N}$-methyl D-aspartate receptor in monkey and mouse cerebral cortex slices. Adv Enzyme Regul 1996;36:229-44.

16. Dixon JF, Hokin LE. Lithium acutely inhibits and chronically upregulates and stabilizes glutamate uptake by presynaptic nerve endings in mouse cerebral cortex. Proc Natl Acad Sci U S A 1998; 95:8363.

17. Nonaka S, Hough CJ, Chuang DM. Chronic lithium treatment robustly protects neurons in the central nervous system against excitotoxicity by inhibiting N-methyl-D-aspartate receptor-mediated calcium influx. Proc Natl Acad Sci U S A 1998;95:2642-7.

18. Alda M. Lithium in the treatment of bipolar disorder: pharmacology and pharmacogenetics. Mol Psychiatry 2015;20:661-70.

19. Lenox RH, Wang L. Molecular basis of lithium action: integration of lithium-responsive signaling and gene expression networks. Mol Psychiatry 2003;8:135-44.

20. Haupt M, et al. Lithium enhances post-stroke blood-brain barrier integrity, activates the MAPK/ERK1/2 pathway and alters immune cell migration in mice. Neuropharmacology 2020;181:108357.

21. Turecki G, et al. Mapping susceptibility genes for bipolar disorder: a pharmacogenetic approach based on excellent response to lithium. Mol Psychiatry 2001;6:570-8.

22. Nunes, A, Stone $\mathrm{W}$, Ardau $\mathrm{R}$ et al., Exemplar scoring identifies genetically separable phenotypes of lithium responsive bipolar disorder. Transl Psychiatry 2020;11:36.

23. Seelan RS, Khalyfa A, Lakshmanan J et al. Deciphering the lithium transcriptome: microarray profiling of lithium-modulated gene expression in human neuronal cells. Neuroscience 2008;151:1184-97.

24. Michael N, Erfurth A, Ohrmann P et al. Acute mania is accompanied by elevated glutamate/glutamine levels within the left dorsolateral prefrontal cortex. Psychopharmacology (Berl) 2003;168:344-6.

25. Ongür D, Jensen JE, Prescot AP et al. Abnormal glutamatergic neurotransmission and neuronal-glial interactions in acute mania. Biol Psychiatry 2008;64:718-26.

26. Ng WX, Lau IY, Graham S et al. Neurobiological evidence for thalamic, hippocampal and related glutamatergic abnormalities in bipolar disorder: a review and synthesis. Neurosci Biobehav Rev 2009;33:336-54.

27. Khayachi A, Gwizdek C, Poupon G et al. Sumoylation regulates FMRP-mediated dendritic spine elimination and maturation. Nat Commun 2018;9:757.

28. Hedya SA, Avula A, Swoboda HD. Lithium toxicity. StatPearls. Treasure Island (FL): StatPearls Publishing: 2020. Available: www. ncbi.nlm.nih.gov/books/NBK499992/ (accessed 2021 May 13).

29. Papa M, Bundman MC, Greenberger V et al. Morphological analysis of dendritic spine development in primary cultures of hippocampal neurons. J Neurosci 1995;15:1-11.

30. Boyer C, Schikorski T, Stevens CF. Comparison of hippocampal dendritic spines in culture and in brain. J Neurosci 1998;18:5294.

31. Takahashi H, Sekino Y, Tanaka S et al. Drebrin-dependent actin clustering in dendritic filopodia governs synaptic targeting of postsynaptic density-95 and dendritic spine morphogenesis. J Neurosci 2003;23:6586-95.

32. Liu ZH, Chuang DM, Smith CB. Lithium ameliorates phenotypic deficits in a mouse model of fragile $\mathrm{X}$ syndrome. Int J Neuropsychopharmacol 2011;14:618-30.

33. Martin PM, Stanley RE, Ross AP et al. DIXDC1 contributes to psychiatric susceptibility by regulating dendritic spine and glutamatergic synapse density via GSK3 and Wnt/beta-catenin signaling. Mol Psychiatry 2018;23:467-75.

34. Tobe BTD, Crain AM, Winquist AM et al. Probing the lithiumresponse pathway in hiPSCs implicates the phosphoregulatory set-point for a cytoskeletal modulator in bipolar pathogenesis. Proc Natl Acad Sci U S A 2017;114:E4462-e4471.

35. Saito N, Shirai Y. Protein kinase C gamma (PKC gamma): function of neuron specific isotype. J Biochem 2002;132:683-7.

36. Callender JA, Newton, AC. Conventional protein kinase $C$ in the brain: 40 years later. Neuronal Signaling 2017;1:NS20160005.

37. Saxena A, Scaini G, Bavaresco DV et al. Role of protein kinase C in bipolar disorder: a review of the current literature. Mol Neuropsychiatry 2017;3:108-24.
38. Freeley M, Kelleher D, Long A. Regulation of protein kinase C function by phosphorylation on conserved and non-conserved sites. Cell Signal 2011;23:753-62.

39. Sossin WS. Isoform specificity of protein kinase Cs in synaptic plasticity. Learn Mem 2007;14:236-46.

40. Salcedo-Tello P, Ortiz-Matamoros A, Arias C. GSK3 function in the brain during development, neuronal plasticity, and neurodegeneration. Int J Alzheimers Dis 2011;2011:189728.

41. Bliss TV, Collingridge GL. A synaptic model of memory: longterm potentiation in the hippocampus. Nature 1993;361:31-9.

42. Penzes P, Cahill ME, Jones KA et al. Dendritic spine pathology in neuropsychiatric disorders. Nat Neurosci 2011;14:285-93.

43. Rosoklija G, G Toomayan, S P Ellis et al. Structural abnormalities of subicular dendrites in subjects with schizophrenia and mood disorders: preliminary findings. Arch Gen Psychiatry 2000; 57:349-56.

44. Konopaske GT, Balu DT, Presti KT et al. Prefrontal cortical dendritic spine pathology in schizophrenia and bipolar disorder. JAMA Psychiatry 2014;71:1323-31.

45. Segal M, Greenberger V, Korkotian E. Formation of dendritic spines in cultured striatal neurons depends on excitatory afferent activity. Eur J Neurosci 2003;17:2573-85.

46. Segal, M. Dendritic spines, synaptic plasticity and neuronal survival: activity shapes dendritic spines to enhance neuronal viability. Eur J Neurosci 2010;31:2178-84.

47. Segal M. Dendritic spines and long-term plasticity. Nat Rev Neurosci 2005;6:277-84

48. Logan RW, McClung CA. Animal models of bipolar mania: the past, present and future. Neuroscience 2016;321:163-88.

49. Lee Y, Zhang Y, Kim S et al. Excitatory and inhibitory synaptic dysfunction in mania: an emerging hypothesis from animal model studies. Exp Mol Med 2018;50:1-11.

50. Nelson AD, Caballero-Florán RN, Rodríguez Díaz J et al. Ankyrin$G$ regulates forebrain connectivity and network synchronization via interaction with GABARAP. Mol Psychiatry 2020;25:28002817.

51. Lek M, Karczewski KJ, Minikel EV et al. Analysis of protein-coding genetic variation in 60,706 humans. Nature 2016;536:285-91.

52. Yang YR, Jung JH, Kim SJ et al. Forebrain-specific ablation of phospholipase Cgamma1 causes manic-like behavior. Mol Psychiatry 2017;22:1473-82.

53. Motohashi N, Ikawa K, Kariya T. GABAB receptors are upregulated by chronic treatment with lithium or carbamazepine. GABA hypothesis of affective disorders? Eur J Pharmacol 1989;166:95-9.

54. Tyagarajan SK, Ghosh H, Yévenes GE et al. Regulation of GABAergic synapse formation and plasticity by GSK3betadependent phosphorylation of gephyrin. Proc Natl Acad Sci U S A 2011;108:379-84

55. Du J, Creson TK, Wu LJ et al. The role of hippocampal GluR1 and GluR2 receptors in manic-like behavior. J Neurosci 2008;28:68-79.

56. Du J, Gray NA, Falke CA et al. Modulation of synaptic plasticity by antimanic agents: the role of AMPA glutamate receptor subunit 1 synaptic expression. J Neurosci 2004;24:6578-89.

57. Gray NA, Du J, Falke CS et al. Lithium regulates total and synaptic expression of the AMPA glutamate receptor GluR2 in vitro and in vivo. Ann N Y Acad Sci 2003;1003:402-4.

58. Sourial-Bassillious N, Rydelius PA, Aperia A et al. Glutamatemediated calcium signaling: a potential target for lithium action. Neuroscience 2009;161:1126-34.

59. Harwood AJ. Lithium and bipolar mood disorder: the inositoldepletion hypothesis revisited. Mol Psychiatry 2005;10:117-26.

60. Wei J, Liu W, Yan Z. Regulation of AMPA receptor trafficking and function by glycogen synthase kinase 3. J Biol Chem 2010; 285:26369-76

61. Abrial E, Lucas G, Scarna $\mathrm{H}$ et al. A role for the PKC signaling system in the pathophysiology and treatment of mood disorders: involvement of a functional imbalance? Mol Neurobiol 2011:44:407-19.

62. Jaworski T, Banach-Kasper E, Gralec K. GSK-3beta at the intersection of neuronal plasticity and neurodegeneration. Neural Plast 2019;2019:4209475.

63. Lee H-K. Synaptic plasticity and phosphorylation. Pharmacol Ther 2006;112:810-32

64. Brambilla, P, Perez J, Barale F et al., GABAergic dysfunction in mood disorders. Mol Psychiatry 2003;8:721-37, 715 . 
65. Ruiz-Veguilla M, Martín-Rodríguez JF, Palomar FJ et al. Trait- and state-dependent cortical inhibitory deficits in bipolar disorder. Bipolar Disord 2016;18:261-71.

66. Hahn CG, Friedman E. Abnormalities in protein kinase $C$ signaling and the pathophysiology of bipolar disorder. Bipolar Disord 1999;1:81-6.

67. Szabo ST, Machado-Vieira R, Yuan P et al. Glutamate receptors as targets of protein kinase $C$ in the pathophysiology and treatment of animal models of Mania. Neuropharmacology 2009; 56:47-55.

68. Einat H, Yuan P, Szabo ST et al. Protein kinase C inhibition by tamoxifen antagonizes manic-like behavior in rats: implications for the development of novel therapeutics for bipolar disorder. Neuropsychobiology 2007;55:123-31.

69. Abrial E, Bétourné A, Etiévant $A$ et al. Protein kinase $C$ inhibition rescues manic-like behaviors and hippocampal cell proliferation deficits in the sleep deprivation model of mania. Int J Neuropsychopharmacol 2015;18:pyu031.
70. Tang W, Cory B, Lim KL et al. The mood stabilizer lithium slows down synaptic vesicle cycling at glutamatergic synapses. bioRxiv 2019;780866.

71. Musante V, Neri E, Feligioni M et al. Presynaptic mGlu1 and mGlu5 autoreceptors facilitate glutamate exocytosis from mouse cortical nerve endings. Neuropharmacology 2008;55:474-82.

72. Pittaluga A. Presynaptic release-regulating mGlu1 receptors in central nervous system. Front Pharmacol 2016;7:295-295.

73. Molcanyi M, Bosche B, Kraitsy K et al. Pitfalls and fallacies interfering with correct identification of embryonic stem cells implanted into the brain after experimental traumatic injury. J Neurosci Methods 2013;215:60-70.

74. Molcanyi M, Mehrjardi NZ, Schäfer U et al. Impurity of stem cell graft by murine embryonic fibroblasts-implications for cell-based therapy of the central nervous system. Front Cell Neurosci 2014;8:257.

75. Mertens J, Wang OW, Kim Y et al. Differential responses to lithium in hyperexcitable neurons from patients with bipolar disorder. Nature 2015;527:95-9. 